\title{
Response of a support system to seismic events: a case study of Mina Uchucchacua, Peru
}

\author{
CV Gonzalez MIRARCO Mining Innovation, Laurentian University, Canada
}

R Beltran Compañía de Minas Buenaventura S.A.A., Peru

J Henning BBA, Canada

\begin{abstract}
The Geomechanics Research Centre (GRC) of MIRARCO at Laurentian University, was contracted by the Chief of Geomechanics at Buenaventura's Uchucchacua Mine to assist in the development of a Seismic Hazard and Geomechanics Risk Assessment Study. This paper defines guidelines and appropriate practices in accordance to MIRARCO expertise as reflected in the Canadian Rockburst Support Handbook (Kaiser et al. 1996) that has assisted the mine in reducing mining-induced hazards, which may also improve the mining performance. The objective of this research was focused on a review of the current state of many mine aspects such as geology, rock mass characteristics, rock support systems, seismic data systems and data collection; all of them directly related with the rock mass behaviour and geomechanics hazards, in order to provide key good practices to add, implement or develop better control of the operation and prevention or mitigation of those hazards. The mine is composed of three production zones: Socorro, Carmen and Huantajalla. The Socorro zone was the focus for this study.

This paper provides a description of study topics that Uchucchacua Mine was advised to consider in order to address hazard awareness over the long-term. This includes integration of stress/microseismic/structural information and tactical ground support design.
\end{abstract}

Keywords: geomechanics hazard, underground risk assessment, seismicity, dynamic rock support

\section{Introduction}

The Uchucchacua Mine, operated by Compañía de Minas Buenaventura S.A.A., is located at the western slope of the Andes Ranges, approximately $25 \mathrm{~km} \mathrm{NE}$ of the town of Oyon, Peru (Figure 1). Uchucchacua is an epigenetic hydrothermal deposit, located in the Jumasha-Celendin formation composed primarily of limestone (Caliza) (DCR Ingenieros S.R. Ltda 2016). The structural shape of the deposit is associated with principal faulting, some of which are mineralised. The primary ore zone is the Gina Socorro vein, a mineralised system of fractures with widths up to $4 \mathrm{~m}$ wide. Where veins merge, the orebody can be up to $16 \mathrm{~m}$ wide. Underground workings are accessed via a portal, located at 4,450 m elevation and from that elevation a depth of 1,500 m approximately. The project has been performed via underground site visits, and later data analysis. The Uchucchacua Mine was visited for the purpose of reviewing geomechanics conditions, standards and practices and interactive discussions with mine personnel. In this paper the consequent analysis is presented.

Section 2 summarises the relevant outcomes of two underground site visits. These visits included reviews of localised ground damage, advice on remediation measures, and identification of potential geohazards zones. During the visits much data were collected to establish a database for each damage event: seismic data related to event and damage description.

Section 3 explores the rock mass characterisation in which the ore zones are associated with sub-vertical faulting, intersecting a limestone rock mass. The rock mass has been characterised using the classification methodology of Bieniawski (1989). 


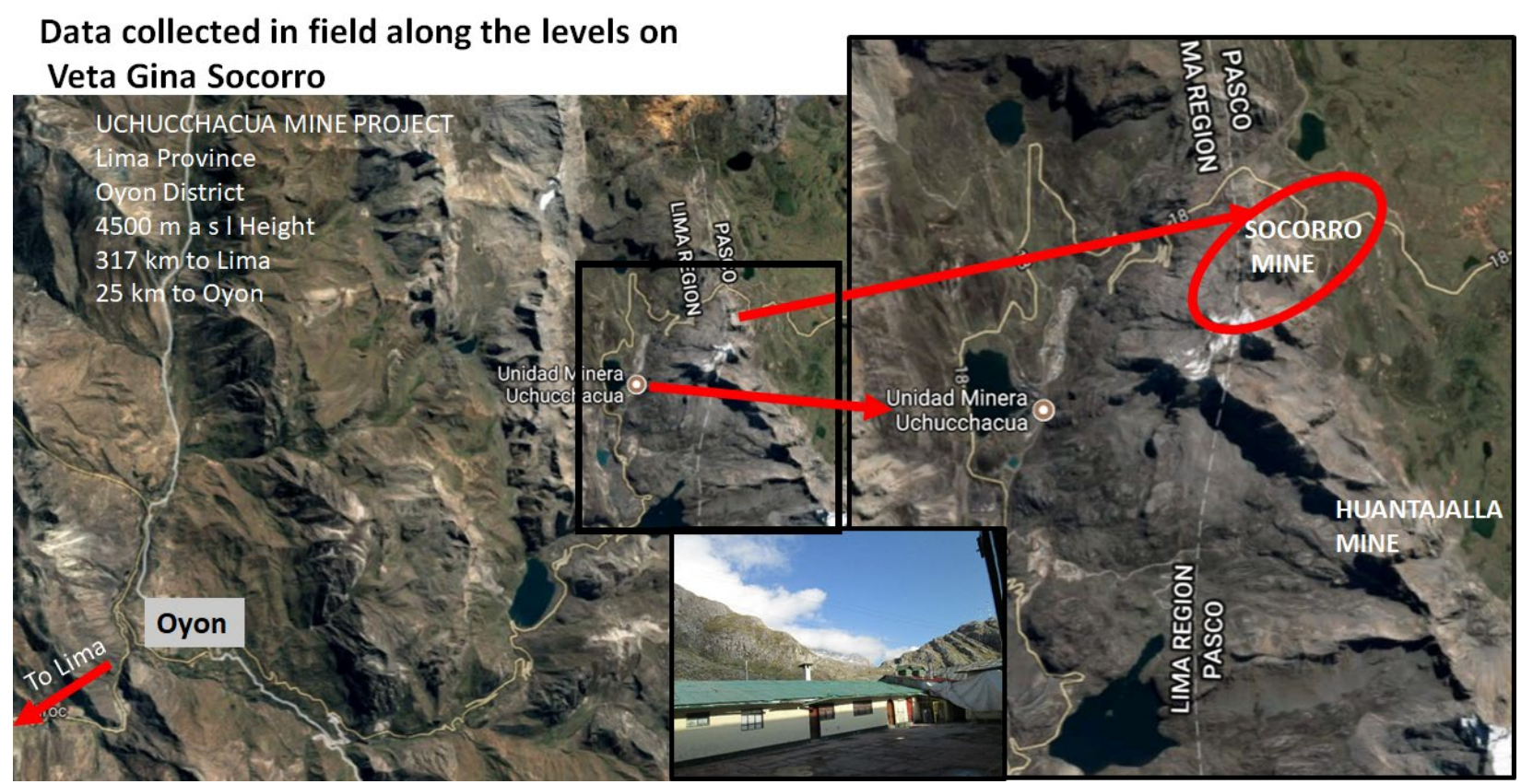

Figure 1 Uchucchacua Mine location

Section 4 presents the analysis of ground support design, local support layout and dimensions, and ground support installation quality. Information collected has been analysed in order to report on deficiencies of currently installed support and suggestions on how to remedy those deficiencies.

Section 5 focuses on seismicity. The review involves the seismic data collection and interpretation. Evaluation of the installed seismic system state, and review of microseismic tendencies. A description of type of seismic events and their link with severity of rockburst damage mechanisms is presented. A preliminary assessment of type of rockburst observed, based on observations and data analysis, is provided.

Section 6 provides discussion about suggestions for items that Uchucchacua Mine should implement in order to reduce the seismic and geomechanics hazard. This includes improving microseismic system accuracy and addressing gaps in ground support practices.

\section{Underground inspection}

\subsection{Visit to rockburst damaged areas}

Excavation damage associated with seismic activity was generated at several levels of the Gina Socorro Ore zone in 2017. Damaged areas were inspected, some of those areas are discussed here in further detail.

\subsubsection{Level 3780 Gallery NE located at 1,000 m depth approximately}

The zone was affected by a seismic event of moment magnitude $3.1 \mathrm{Mw}$ and an epicentre at $250 \mathrm{~m}$ from the damaged locations. The damaged zone extends along $100 \mathrm{~m}$ of the drift, as indicated in green (Figure 2) in the plan view. Rockburst damage at the base of a pillar was observed (bottom left picture, Figure 2). Tangential wall strain, likely due to mining induced deformation was observed (top left picture, Figure 2). Along the $100 \mathrm{~m}$ of damaged drift, broken rock at the top corners appeared more pronounced as a consequence of a sudden strain in walls. At the time of the visit, deformation continued gradually which was evidenced in the repaired shotcrete (top right picture, Figure 2). In this particular area, the presence of calcite veins is denser. 


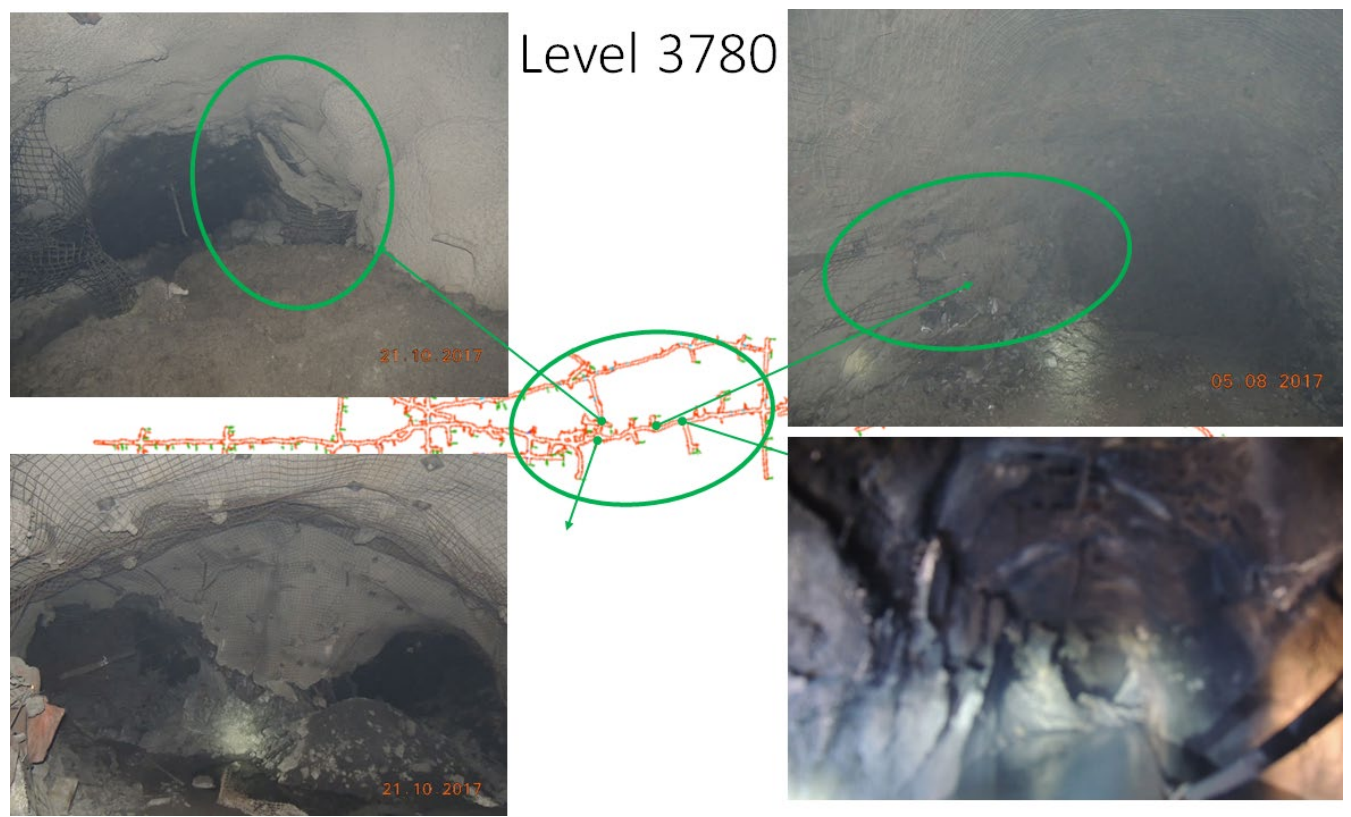

Figure 2 Inspection at Level 3780 Gallery NE

\subsubsection{Level 6980 at 1,140 $\mathrm{m}$ depth approximately}

An intersection between two mineralised fault systems occurs above this sublevel. This has generated a natural structural wedge above the drift roof, as shown schematically in Figure 3. Damage occurred as a result of the same seismic event of moment magnitude $3.1 \mathrm{Mw}$. The drift roof collapsed along more than $100 \mathrm{~m}$ length of the drift, resulting in a 4-6 $\mathrm{m}$ high structurally controlled cavity. Ongoing, active deformation at this location is identified by fresh cracking of the shotcrete applied during rehabilitation.
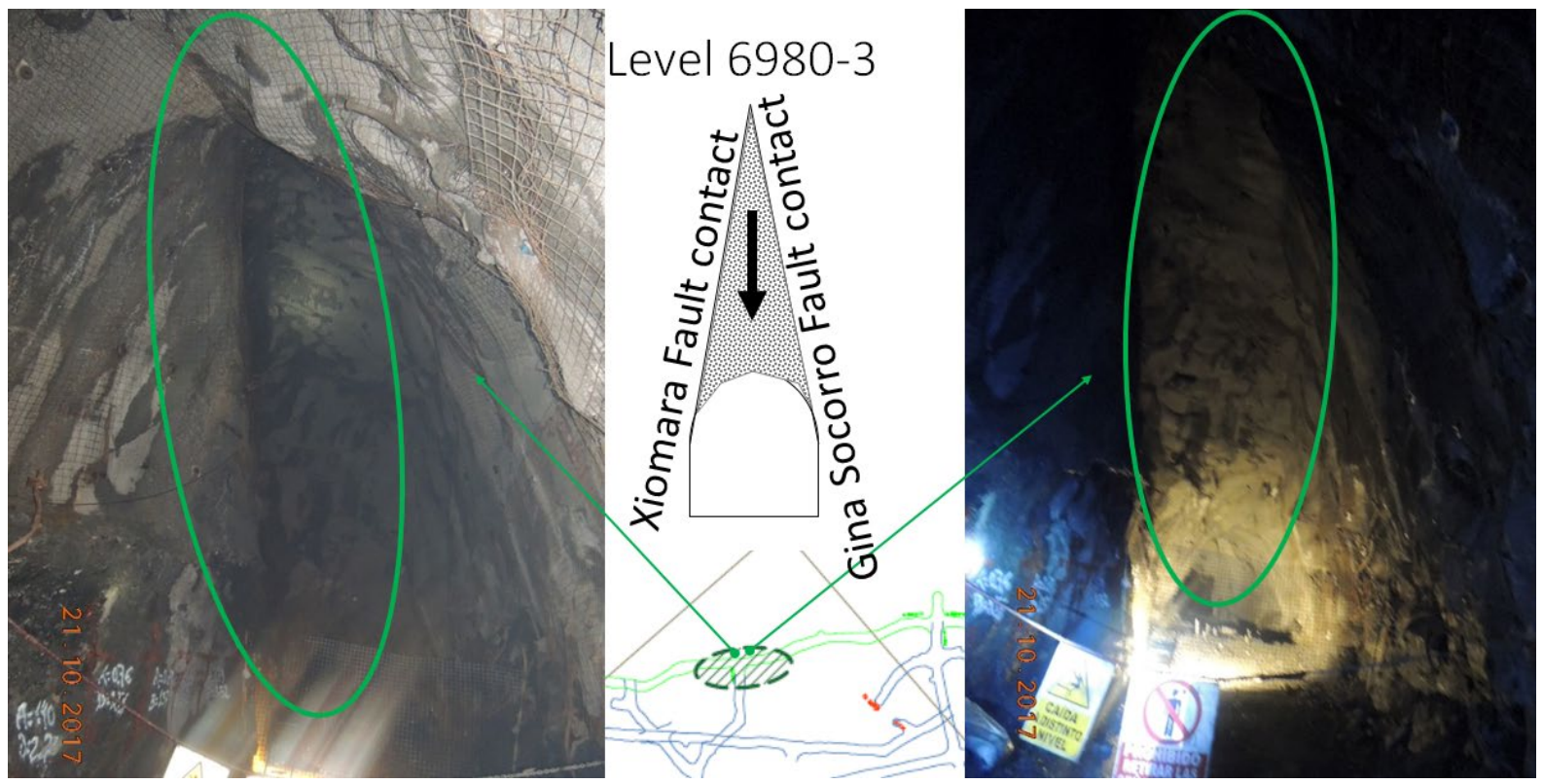

Figure 3 Inspections at Sublevel 6980

\subsubsection{Level 3710 Gallery SW at 1,350 m depth approximately}

Damage at this level is associated with seismicity. The drift, primarily at the base of the walls was damaged. Active bulking (lateral deformation) of the walls was observed, along with cracking of recently placed shotcrete, as shown in the top right picture of Figure 4. A well-defined structural wedge intersection was identified during the site inspection, requiring scaling and rehabilitation by the mine operation. 


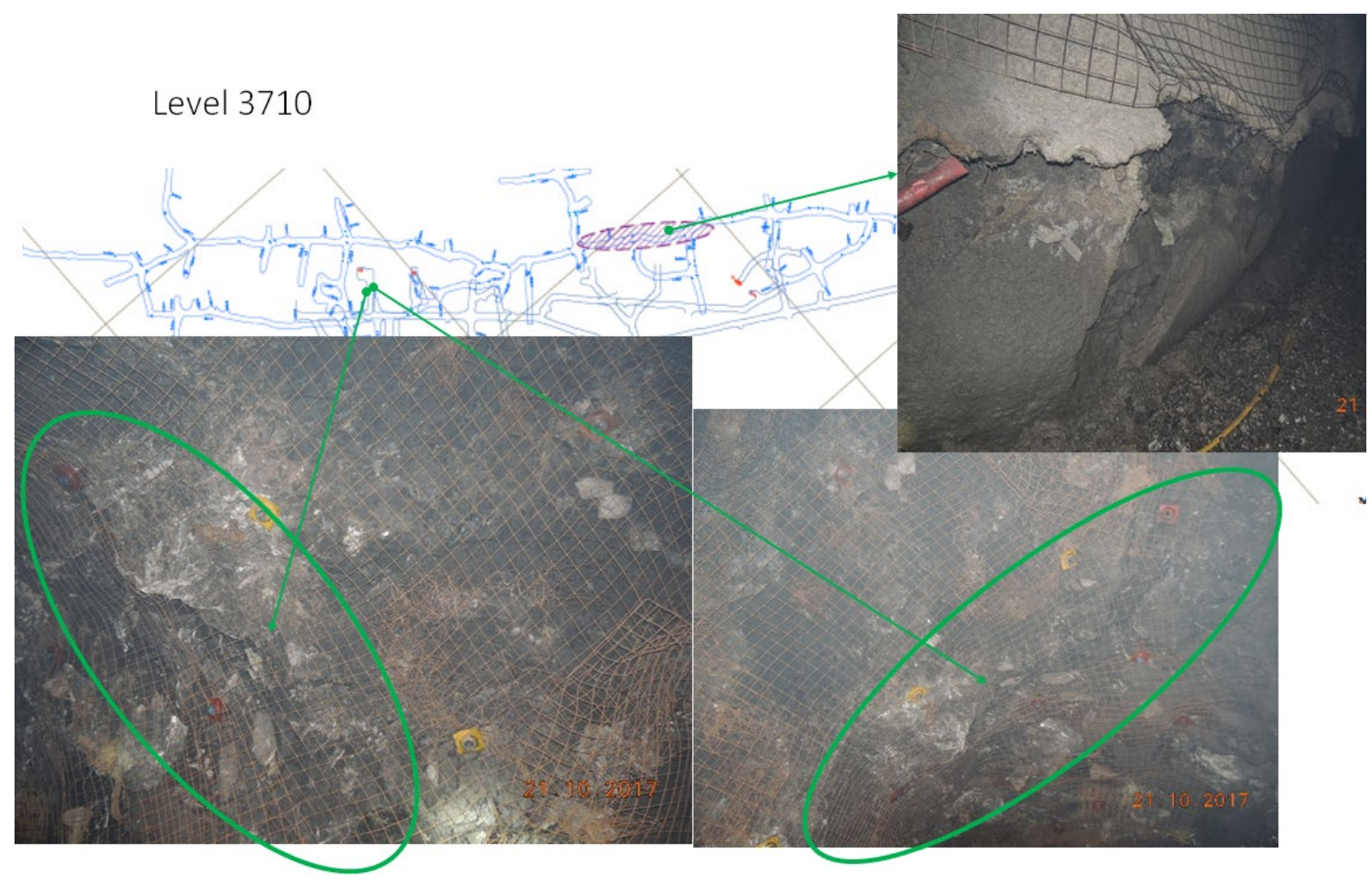

Figure $4 \quad$ Inspections at Level 3710

\subsection{Stress setting (observational)}

Rock strength measurements were available from the Schmidt Hammer method, point load testing (PLT), and a limited number of uniaxial compressive strength (UCS) tests. A significant discrepancy between the PLT and UCS methods was found. A selection of core samples was obtained for the purpose of UCS testing. The observations did not provide insight into the principal stress direction and field tests to measure it were recommended.

Rock damage associated with rock mass structure (joint persistence and spacing of joint sets), is a driving mechanism identified at Level 6980 at 1,140 m depth (section 2.1.2). The types of damage typically associated with stress-generated damage would include: preferential crushing or deformation along drift corners, spalling, rock noise ('working ground', described as cracking or popping), and systematic accumulation of loose rock behind screening Diederichs (1999). The support components that were in use to form the overall support system is detailed in Section 4.

- The initiation of minor stress-associated damage may be mitigated by the systematic installation of 'super' SplitSets (larger $47 \mathrm{~mm} \varnothing$ Splitsets with respect to standard SplitSets at $40 \mathrm{~mm} \varnothing$ ), mesh and shotcrete in longer-term accesses.

- Since the SplitSets yield (creep) as the rock mass deforms, other visible indicators of stress-related damage, such as rockbolt damage (failed bearing plates) were not apparent.

\subsubsection{Anticipated rock behaviour}

Excavations in hard rock can be categorised into nine classes as illustrated by the matrix of instability modes in Figure 5 (Kaiser et al. 1996). A red box superimposed on Figure 5 illustrates the range of rock behaviour modes observed in the excavations visited at Uchucchacua Mine. In strong, hard rock such as limestone host rock, structurally controlled failure processes dominate at shallow to intermediate depth typically to around $750 \mathrm{~m}$, or at low to intermediate induced stress (given on right side of the matrix). 


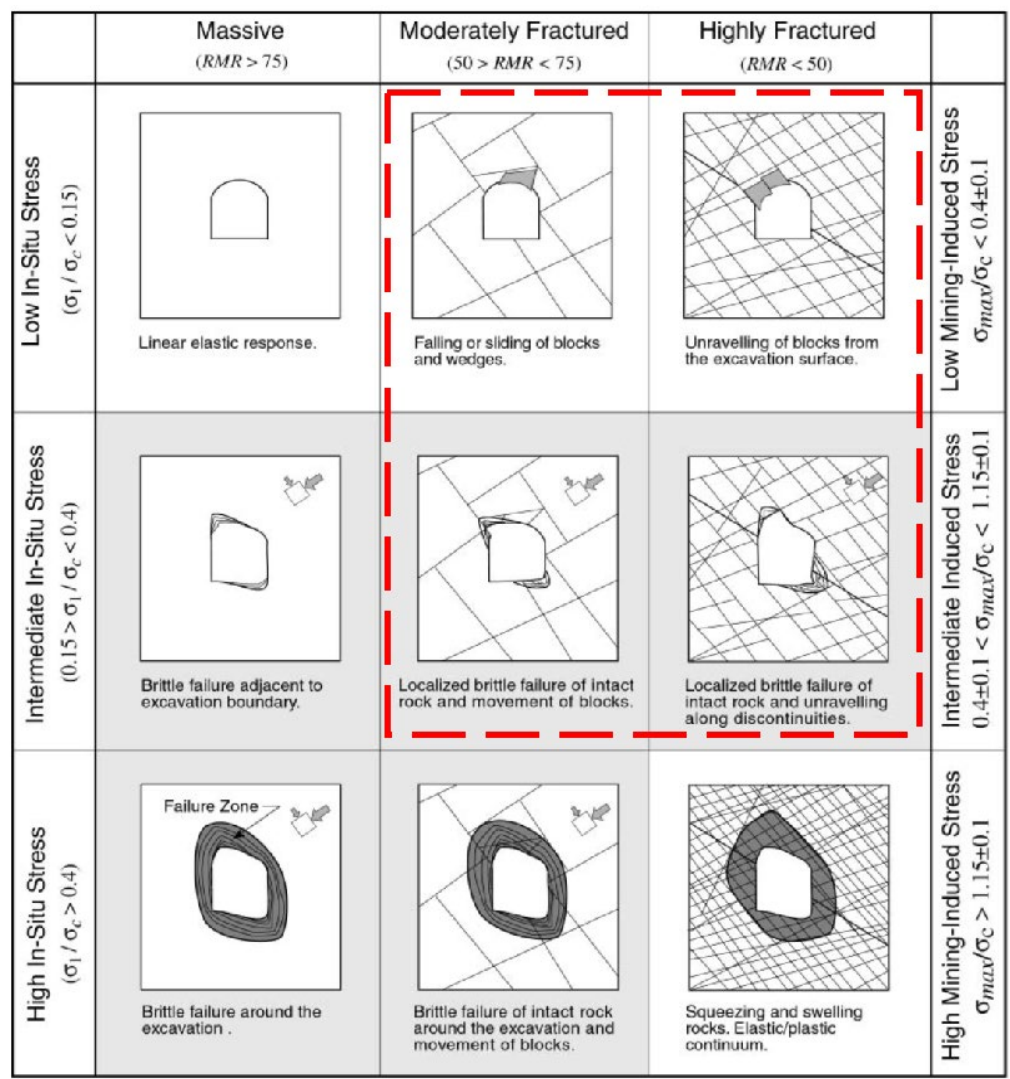

Figure 5 Rock failure mode matrix (Kaiser et al. 1996); the range of rock behaviour modes observed at Uchucchacua Mine indicated by the red outline

Typically, when 0.4 UCS $<\sigma_{\max }<\sim 0.8$ UCS, stress-driven rock fracturing processes starts overlapping with structurally-controlled processes. And when $\sigma_{\max }>\sim 0.8$ UCS the conditions are extremely difficult with violent failure. The degree of rock mass fracturing depends on the stress level and the stress orientation relative to existing rock mass weaknesses (non-persistent joints, foliations etc.). At these depths, the rock mass starts to deteriorate when stresses are unfavourably oriented. If the rock mass surrounding the tunnel is heavily fractured, it tends to increase in volume or bulk causing closure of the opening. Stress-driven behaviour dominates when the stress level is sufficient to cause failure of intact rock.

At the time of the visits no field stress measurements were performed so it was strongly recommended to carry out a stress measurement campaign that provided a general and localised stress distribution dataset.

\subsection{Mining method}

Mining in the Gina Socorro zone was initially performed using the cut-and-fill mining method. In 2016, the mine adopted a bench and fill (longhole) mining method, with sublevels at $10 \mathrm{~m}$ vertical spacing (Buenaventura 2017). Small diameter blastholes are drilled down from the upper sill elevation.

- Stopes are mined to a strike length of $25 \mathrm{~m}$. Stope widths are commonly 4-6 m, however widths up to $\sim 15 \mathrm{~m}$ have been mined. Other than standard primary excavation support (typically $2.4 \mathrm{~m}$ long super SplitSets), no additional wall reinforcement (such as cable bolts) was installed.

- The wider stopes were backfilled with cemented rockfill (CRF). UCS testing of CRF cylinders generates strengths of $>3 \mathrm{MPa}$ at seven days cure.

- Some of the $\sim 6 \mathrm{~m}$-wide bench and fill stopes visited exhibited little evidence of hanging wall overbreak (caving dilution). This suggests a competent rock mass with reasonable stope dimensions. Damaged mesh strands and loose rock accumulation above mesh adjacent to the stope crest is likely associated with stope blast damage, rather than stress damage. 
- Note that stress damages (such as squeezing holes (requiring re-drilling or casing), unravelling of the stope hanging wall, and increased accumulation of loose rock behind non-shotcreted stope sill drifts), would be expected as a bench and fill stope advances up towards the overlying mined stopes.

\section{Rock mass characteristics}

The rock mass at Uchucchacua Mine was typically characterised using the classification methodology of Bieniawski (1989).

\subsection{Field mapping (rock mass characterisation)}

Six mapping points were carried out during the visits. The rock mass characterisation was performed using three techniques: Rock Mass Rating (RMR), Q and Geological Strength Index (GSI). Each classification system differs in methodology and factors assessed.

- The RMR method can capture general changes in joint spacing, joint condition and water flow. The rock strength rarely changes.

- The Q method can capture important changes in joint condition, such as the presence of clay infill. Compared to the RMR method, the local severity of water inflow can be better captured using the Q approach.

- The GSI approach does not consider the negative influence of water seepage/flow across structure. However, GSI is an effective and easily used method for capturing and comparing block size (joint spacing in 3D space) and the severity of joint surface alteration.

The majority of the rock mass has been considered as Type 3 (RMR 41-60), with some indications of reduced rock mass quality at depth (Type 4: RMR 30-40; no low range Type 4 (i.e. RMR 21-30) was evident). The reduction in rock mass quality is associated with:

1. Decreased joint spacing (resulting in a blockier rock mass).

2. An increase in joint persistence.

3. A potential decrease in joint infill quality with depth.

\section{$4 \quad$ Ground support}

\subsection{Ground support practices}

Ground support standards at Uchucchacua Mine take into account:

- Dimensions of the excavation dimension (typically up to $4 \mathrm{~m} \mathrm{~h} \times 4 \mathrm{~m}$ w; arched back).

- Type or service life of the excavation (classified as either Permanent or Temporary use). Permanent excavations include ramps and principal access drifts. Temporary excavations include stope accesses and sill drifts.

- Type of drill used for rockbolt installation - either mechanised drill (jumbo or bolter), or handheld drill (jackleg and stoper). The preference of the mine is to install ground support with mechanised equipment wherever excavation dimensions permit. Smaller $2.7 \mathrm{~m} \mathrm{~h} \times 2.7 \mathrm{~m}$ w accesses are developed using handheld drills.

- Rock mass quality, based on RMR criteria.

The types of ground support rockbolt employed at the mine are: SplitSets, providing the primary ground reinforcement. Standard SplitSets $(40 \mathrm{~mm} \varnothing)$ are installed using handheld drills. Larger $47 \mathrm{~mm} \varnothing$ SplitSets 
('Super SplitSets') are installed with mechanised equipment. The weldmesh screening used at Uchucchacua Mine is 12 gauge. Additional support is shotcrete $0.05-0.075 \mathrm{~m}$ thick.

\subsection{Function of rockbolt support}

The function of rockbolt support is to provide reinforcement to the rock mass against both structurally defined wedge instability (moderate to large wedges) and stress-driven spalling. Taking the load-deformation capacity (Figure 6a) into consideration, there are essentially four classes of rockbolts: resin-grouted rebar; mechanical rockbolt with a mechanical point anchor; friction bolts (Swellex or SplitSet) and cable bolt (tendons).

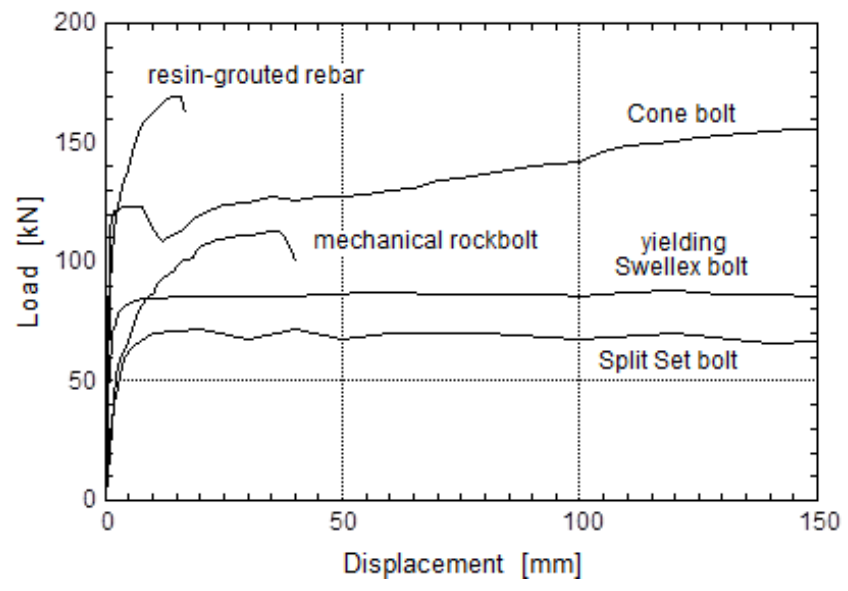

(a)

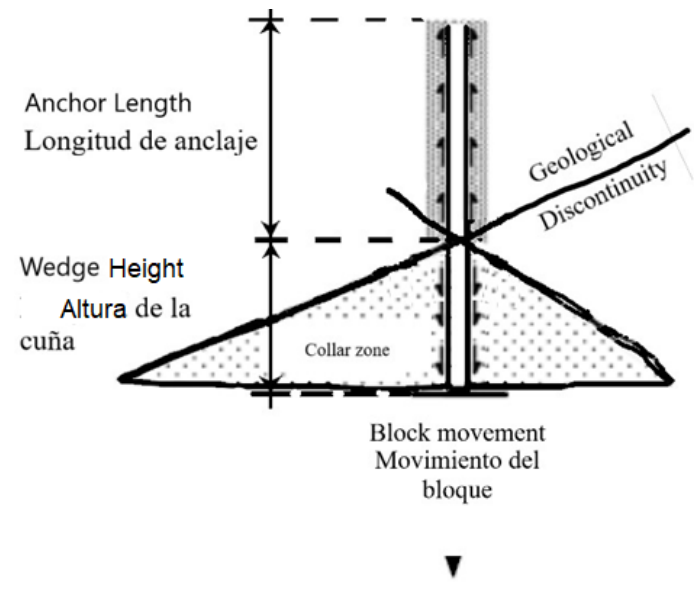

(b)

Figure 6 (a) Classification of rockbolt types as a function of load-deformation trends (Kaiser \& Cai 2018); (b) example of a SplitSet bolt installed through a structural wedge (Hoek et al. 1995)

Tendon refers to flexible support elements whereas rockbolt is used for the class of rigid elements. Swellex and SplitSets are normally considered to be the same class as both use mechanical friction to resist applied loads. The friction bolts SplitSet stabiliser is a slotted steel tube, with one end tapered for easy insertion into a drillhole. The other end has a welded ring flange to hold the bearing plate. SplitSet bolts and bearing plates should be made in accordance with the standard ASTM F432-13. Rebar and Swellex both require approximately $300 \mathrm{~mm}$ of contact between the bolt and competent rock to mobilise full support load capacity. By comparison, SplitSet capacity is related to the total length of the bolt that is in contact with competent rock. For the example shown in Figure6b, where a bolt extends through a structural wedge, SplitSet capacity is related to only the bolt length above the wedge ('anchor length'), or $~ 50 \%$ of maximum capacity.

\subsection{SplitSet field testing}

The pull test is the method which is commonly used for determining the anchorage capacity of SplitSets. Bolts are tested at any time after installation (ideally at the time of installation) by applying a load to the pull collar and increasing it until the bolt slips. Records of a total of 507 individual SplitSet pull tests performed at 73 test locations were reviewed. We noted that test location with respect to excavation surface was not indicated. No tests performed in the ore zone (vein) rock mass were documented. Additional testing in this rock mass range is recommended.

Super SplitSets (installed with mechanised equipment):

- An average capacity of $12.52 \mathrm{t}(5.95 \mathrm{t} / \mathrm{m})$ was obtained from pull testing of $2.13 \mathrm{~m}$-long Super SplitSets $(47 \mathrm{~mm} \varnothing)$ in Type 3 rock mass.

- Pull testing of $2.13 \mathrm{~m}$-long Super SplitSets $(47 \mathrm{~mm} \varnothing)$ in Class 4 (labelled as Class 3-4 rock) indicates a reduction of yield capacity from $\sim 12.52 \mathrm{t}$ to $\sim 9.89 \mathrm{t}(4.76 \mathrm{t} / \mathrm{m})$. 
$40 \mathrm{~mm} \varnothing$ SplitSets (installed with handheld equipment):

- Extensive testing (343 individual tests) has been performed with $1.52 \mathrm{~m}$ SplitSets, installed in Type 3 rock mass. Average capacity of $5.72 \mathrm{t}(3.87 \mathrm{t} / \mathrm{m})$ was obtained.

- Very limited pull testing (eight tests) of standard SplitSets has been performed in Class 4 rock (labelled as Class 3-4), where an average capacity of $5.44 \mathrm{t}(3.57 \mathrm{t} / \mathrm{m})$ was obtained.

Test results are within expected ranges. Figure 7 shows relationships between pull-out capacity, rock characteristics and borehole diameter from a wide range of documented testing of standard SplitSets. Values obtained from pull testing in Type 3 rock mass are comparable with anticipated values for competent rock.

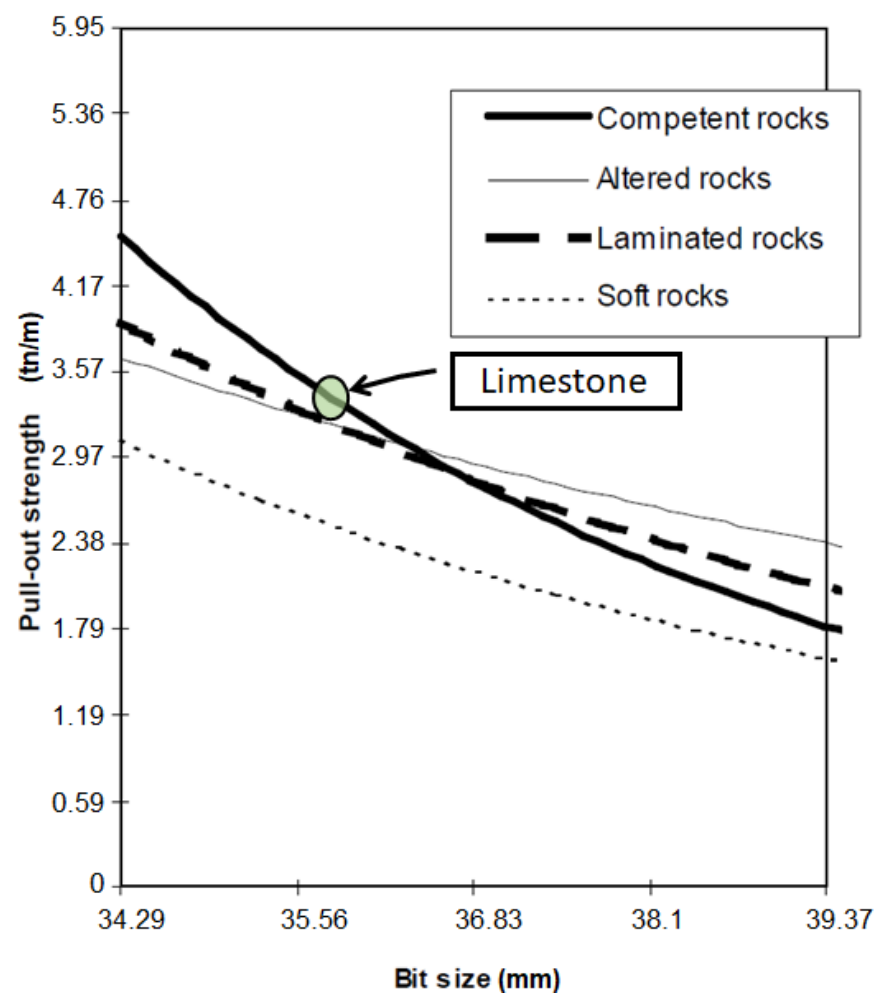

Figure 7 Comparison of $40 \mathrm{~mm} \varnothing$ SplitSet pull test results $(5.72 \mathrm{t} / 1.52 \mathrm{~m})$ against published results (modified from Tomory et al. 1998)

\subsection{Estimation of roof stability (Factor of Safety)}

The load Factor of Safety (FS) is defined as:

$$
\text { FS load }=\frac{\text { Support Load Capacity }}{\text { Load Demand }}
$$

where: Support Load Capacity refers to the effective capacity of the rockbolts that remain above an anticipated thickness of damaged ground, and Load Demand refers to the potential mass of the volume of damaged rock that is being supported by the rockbolt.

In general, FS covers the design of both static and dynamic loads. Under dynamic loading conditions, such as from large mass blasting vibrations or seismic vibrations, the dynamic acceleration will increase load demand. Acceptable minimum values of FS for ground support design are:

"The value of the factor of safety, which is considered acceptable for a design, is usually established from previous experience of successful designs. A factor of safety of 1.3 would generally be considered adequate for a temporary mine opening while a value of 1.5 to 2.0 may be required for a 'permanent' excavation." Hoek et al. (1995) 
Examples of 'permanent' excavation include: ramps, electrical substations, maintenance shops etc. FS values for ground support design are generated from the relationship described in Equation 1. Support Load Capacity considers pull test values, along with an effective bolt capacity. Since SplitSet capacity varies with effective bolt length, load demand considers the thickness of a potentially unstable zone, systematic bolting pattern $(1.2 \times 1.2 \mathrm{~m}$ to Type 3 and $1 \times 1 \mathrm{~m}$ to Type 4$)$ and rock density. For a $4 \mathrm{~m}$-wide excavation, the potential unstable zone was to this case conservatively estimated as $\sim 0.6 \mathrm{~m}$ depth (Type 3 rock mass), and $0.8 \mathrm{~m}$ depth (Type 3-4 and Type 4 rock mass). As result of the calculation:

- The ground support designs represent appropriate FS for permanent excavations, supported by Super SplitSets, in Type 3 and Type 4 rock and for excavations in Type 3 rock, supported by standard SplitSets.

- The FS of Class 4 Temporary Excavations is sensitive to bolt capacity. Average yield strength in Type 3-4 rock (eight tests performed) of $5.44 \mathrm{t} / 1.52 \mathrm{~m}$-long bolt resulted in FS of 1.3.

\section{$5 \quad$ Seismicity}

A seismic event is a transient dynamic stress wave caused by failure of fracturing in a rock mass or slip on a pre-existing major structure. Common seismic sources in underground mines include: rock mass deformation associated with new excavations, variation of rock properties at lithological contacts, a change in shear or normal (confining) stress along geological features (faults), causing the feature to slip, and pillar crushing.

\subsection{Microiseismic network, Gina Socorro zone}

A microseismic system in Uchucchacua Mine is composed by a paladin panel which is a digital microseismic recorder and a set of geophones which are the seismic sensors that detect and measure small ground vibrations caused during mining operations. They can be deployed in various configurations around a zone of interest to provide the best possible detection coverage. All of them can be connected to a laptop by using an optic fibre. The sensors were found installed in close proximity (typically within $25 \mathrm{~m}$ ) to the stopes. Since installation, sources of seismicity at distances up to $300 \mathrm{~m}$ from the mine workings have been detected. However, accuracy of the source locations is negatively affected by the limited lateral extent of the seismic sensor array. For example, the scatter of microseismic events shown in Figure 8 contains numerous questionable event locations with far beyond the sensor array (shading area).

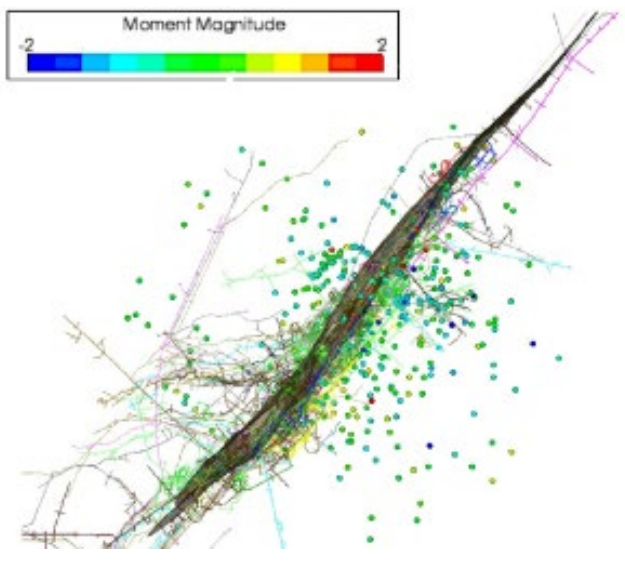

Plan view

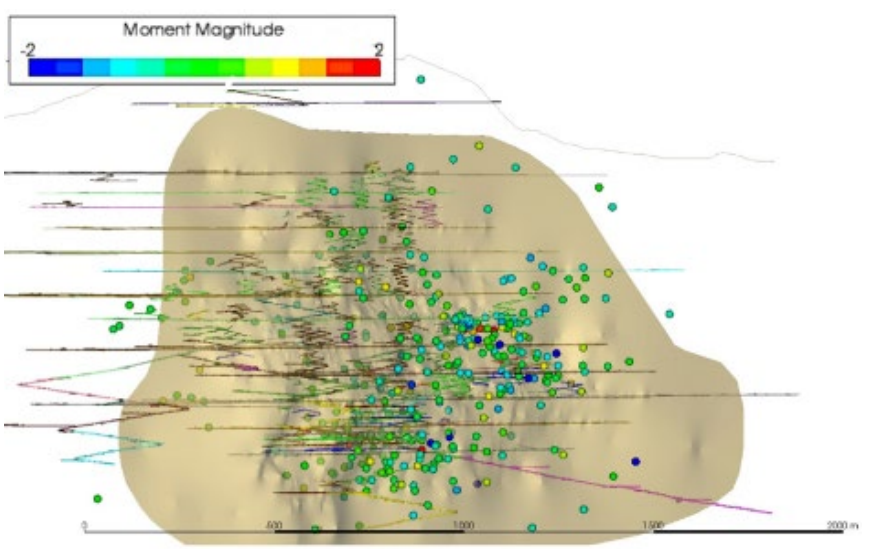

Longitudinal Section

Figure 8 Scatter of microseismic activity (all events, November 2017). Moment magnitude range: -2 to $+2 \mathrm{Mw}$

Larger events were recorded in June 2017 with moment magnitude $+1.97 \mathrm{Mw}$ and $+1.56 \mathrm{Mw}$. Some of them located in close proximity (within a $\sim 250 \mathrm{~m}$ envelope) to each other. Based on photos provided (Figure 9), the primary ground support practices applied in Gallery 6980 were adequate to maintain excavation stability for an event of this magnitude located at $\sim 280 \mathrm{~m}$ from that gallery. 


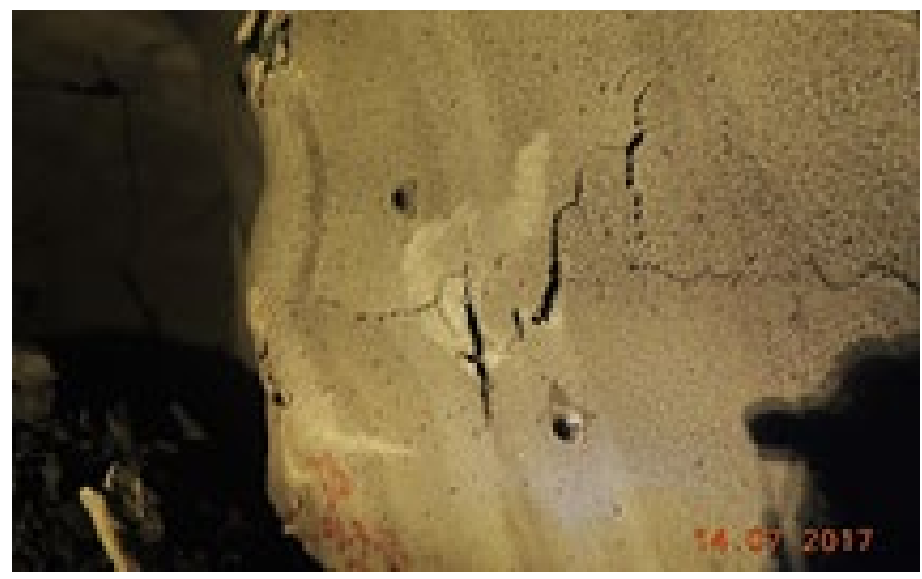

Figure 9 Excavation damage associated with magnitude 1.9 event, June 2017. Ground support includes Super SplitSets and shotcrete. Photo source: Uchucchacua Mine

In August 2017, a significant seismic event with magnitude moment 3.15 Mw occurred. The seismic system located the epicentre of this event at $203 \mathrm{~m}$ relative to Gallery 6980 as shown in Figure 10. Excavation damages associated with this event were extensive. Common damages included falls of ground of depth up to $\sim 1 \mathrm{~m}$ from around the SplitSet rockbolts. Unravelling occurred as the capacity of the 12 gauge mesh was exceeded.

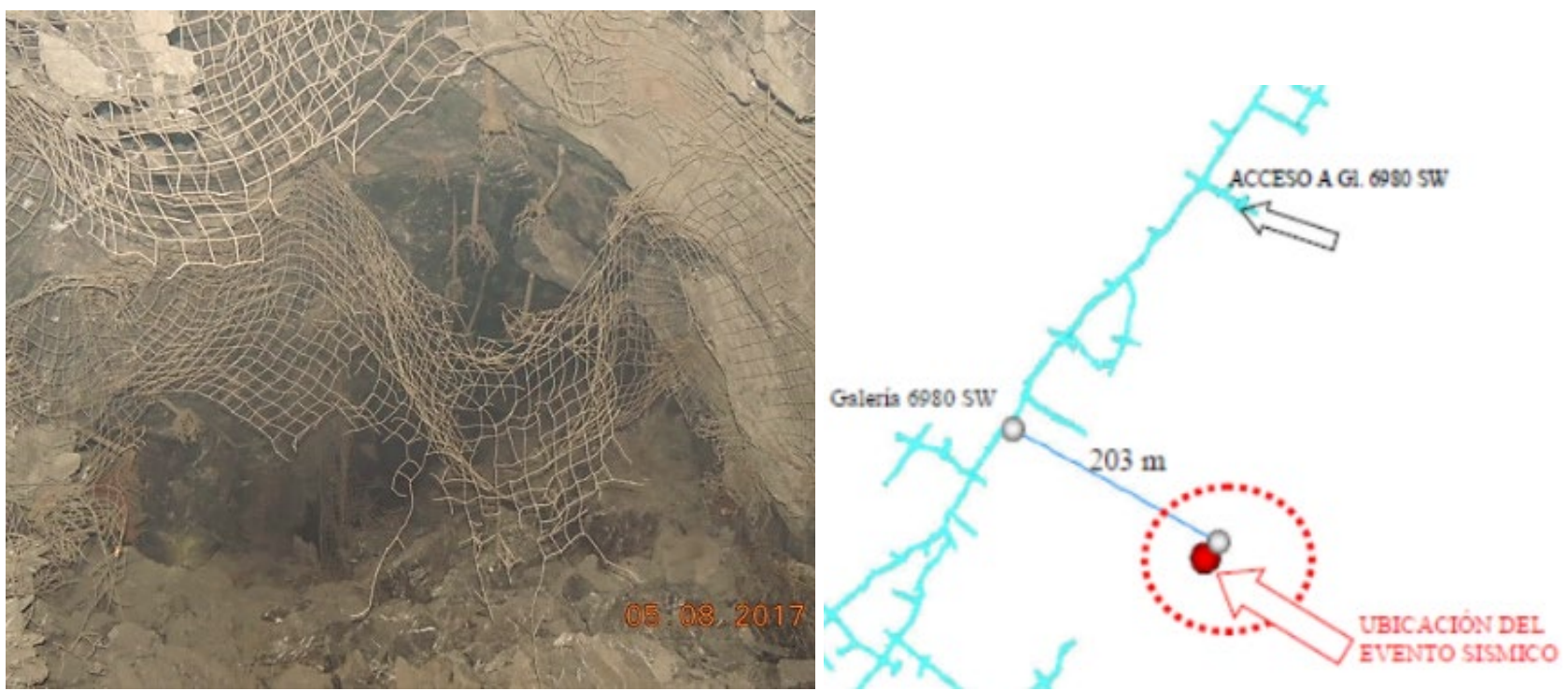

Figure 10 Gallery 6980 showing estimated seismic epicentre (3.15 Mw). Excavation damage associated with the event

\subsection{Classes of rockburst}

A seismic event that results in visible rock mass damage is called a rockburst. The Rockburst Research Handbook (CAMIRO Mining Division \& Mining Research Directorate 1995) documents five years of Canadian rockburst research in hard rock mines.

Common mechanisms that can be associated with seismicity and rockbursting are: strain burst; buckling, pillar burst, shear rupture, and fault slip mechanism (Ortlepp \& Stacey 1994).

- Fault slip burst is a rockburst caused by the sudden, earthquake-like movement along a weakness in the rock mass (e.g. a fault) that causes a sudden change in the stress field within the volume of influence and radiates energy in the form of ground vibration. Fault slip rockbursts are associated with geologic discontinuities. The mining activity can reduce shear resistance along the fault and 
can increase the shear force along the fault, leading to slip. Damage generated from these events tend to be severe, affecting a large area. Typical seismic Richter magnitudes $\left(\mathrm{M}_{\mathrm{L}}\right)$ range $\sim 2.5 \mathrm{M}$.

- Pillar burst occurs when static or dynamic stresses exceed rock mass strength, leading to the sudden failure of the pillar. A pillar burst is the result of local stress redistribution, leading to a violent failure of an over-stressed pillar(s). With the sudden stress redistribution onto nearby pillars, a domino effect of pillar failures may result. Typical range of seismicity: $\mathrm{M}_{\mathrm{L}} \sim 1.0-2.5$.

- Strain burst is encountered when static or dynamic stresses exceed the rock mass strength in the wall of an excavation. In this case, the damage consists of the brittle, violent failure of the unsupported or supported rock mass near the excavation wall. Face bursting is a common form of strain burst, caused by the accumulation of strain energy. Typical range of seismicity, Richter Magnitude $\left(\mathrm{M}_{\mathrm{L}}\right)$ is $-0.2-0$.

- Buckling most often occurs in laminated or transversely anisotropic rock. Damage occurs as accumulated strain energy stored in thin slabs of column of rock is suddenly released. Damage, often in the form of outward expulsion of pre-existing slabs, can occur anywhere around the periphery of the opening. Typical range of seismicity: $M_{L} \sim 0-1.5$.

- Shear rupture is a shear failure through intact rock, free of joints. Seismicity occurs when the stresses exceed the shear strength of the rock. Typical range of seismicity: $\mathrm{M}_{\mathrm{L}} \sim 2.0-3.5$.

Based on underground inspections of active mine workings at Uchucchacua Mine, the apparent absence of significant stress generated damage in excavation surfaces suggests that pillar bursting and strain bursting are unlikely to be the sources of the larger seismic activity generated.

A fault slip rockburst mechanism is suggested by: (i) the existence of faults and splay faults in proximity to an extensively mined ore zone; (ii) an apparent relationship with microseismic activity and the rainy season. The fault slip seismicity could potentially be associated with either unclamping, or day-lighting and details of these phenomena are available in Castro et al. (2009). At the time of the visits the mine did not have triaxial sensors installed, what could help in determining the source of the seismicity.

\section{Discussion}

\subsection{Knowledge gaps - mineralised zone}

In lower quality ground, SplitSet capacity (yield load) is often reduced. However, no examples of SplitSet testing in ore were identified in the SplitSet pull test database provided. It was recommended to:

- Perform SplitSet and Super SplitSet pull testing in ore zone rock mass. Document ore zone width at each test location.

- If support performance in the mineralised (ore) zones differs significantly from the (limestone) test results, modifications to primary support designs may be required.

Field observations, supported by the rock quality designation (RQD) drillcore logs indicate that the limestone in close proximity to the mineralised zone tends to increase in quality, becoming more massive, darker in colour, and potentially stronger. The mineralised zone itself is of poor quality. The elevated rock quality adjacent to the mineralised zone reflects the metamorphic alteration of the limestone towards a marble as a result of the mineralised zone inclusion. It was recommended to:

- Compile GSI, Q and RMR data systematically via standard worksite geotechnical inspections.

- Since the large damaging seismic events are related to structural features, the mine should also investigate a structural model.

- Note that rock mass quality may be further reduced in the central core of wide-span stopes. 
- It is imperative to determine the rock mass stress tensor range via stress measurement in situ testing.

\subsection{Microseismic system optimisation}

At the time of the visit, the majority of sensors were installed in close proximity to the ore zone. Ideally, some sensors need to be installed further into the hanging wall and footwall, thus improving source location accuracy. Uchucchacua Mine worked hard to ensure source location accuracy and improved all equipment and data acquisition.

Maintaining the microseismic system and interpreting meaningful data trends is a skill that requires time to master. Once non-seismic events (such as vibrations from production blasting) and potentially erroneous events (such as events far outside the sensor network, or events triggering only a limited number of sensors), microseismic relationships with factors such as mine sequencing, stope blasting, specific regions (such as locations of suspected 'active' structures), seasonal rains or snowmelt etc. can be developed.

When a seismic event triggers damage (rockburst), the mine also needs to have protocols in place for safe re-entry into the affected areas. Re-entry protocol will vary with magnitude of seismic event, source location, the installed ground support system, and attenuation rate of microseismic activity.

\subsection{Numerical modelling and data integration}

The 3D numerical modelling of Uchucchacua Mine excavations was recommended. This numerical model, when calibrated against known/observed damage (such as the pillar damage on maintenance shop, or instability/caving of wide span bench and fill stopes), will allow for greater understanding of induced stress distribution as a function of mining sequence:

- The 3D model could incorporate features such as modelling of fault shear stress and visualisation of microseismic data for greater understanding of seismic risk.

- 3D stress information can be implemented into Phase2 (RS2), for improved, 2D non-linear modelling on specific sections.

\subsection{Ground support gaps}

According to the Rockburst Research Handbook (CAMIRO Mining Division \& Mining Research Directorate 1995) rockburst damage is caused by one or more of the following mechanisms: rock bulking due to fracturing, rock ejection due to seismic energy transfer and rockfalls induced by seismic shaking. Evidence indicates that recent damage at Uchucchacua Mine is associated with these three mechanisms. Figure 11 presents a simplified view of three primary support functions: to reinforce the rock mass; to retain broken rock; and to securely hold or tie back the retaining element(s) (McCreath \& Kaiser 1992). While each element of a support system may simultaneously provide more than one of these functions, it is convenient to consider each function separately.

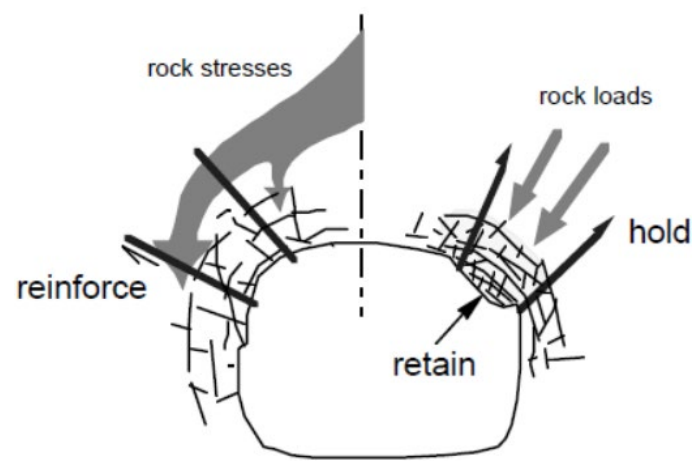

Figure 11 Three primary functions of support elements (CAMIRO Mining Division \& Mining Research Directorate 1995) 
The goal of reinforcing the rock mass is to strengthen it and to prevent loss of strength, thus enabling the rock mass to support itself (Hoek \& Brown 1980). Reinforcing elements such as SplitSet bolts, yielding Swellex or conebolts, may behave as ductile or yielding elements under high deformation conditions. Alternatively, fully grouted rebars behave as stiff support elements.

While retaining broken rock may be required for safety reasons, it becomes essential under high stress conditions to prevent progressive failure processes leading to unravelling of the rock mass. At Uchucchacua Mine, the retaining function was limited by the relatively small gauge of weldmesh screening (12 gauge). The retaining function is enhanced with shotcrete application.

The holding function is needed to tie the retaining elements of the support system back to stable ground, and to prevent gravity-driven falls of ground both during and after a rockburst. Under conditions of large imposed (relative) displacements between the anchor and the head of the holding element, a yielding element is required. In some cases, as long as the holding element can yield sufficiently, it will not be required to absorb much energy -- just being able to move is all that is required. At Uchucchacua Mine, the holding function was generally not addressed with second-pass reinforcement.

\subsubsection{Secondary support for holding function}

There are a number of commercially available yieldable rockbolts suitable for dynamic conditions; however, the weakest link in a ground support system is often the surface support, including the connections with the rockbolts. Surface rock support serves two main purposes in underground installations: it retains loose material and distributes loads between rockbolts.

In a dynamic environment the load transfer from the surface support to the rockbolts is the primary requirement for the surface support to ensure that the system works as a whole.

Dynamic support types (holding function) would be only installed in locations where potential rockburst damage hazard is anticipated. These locations can be identified as rockburst-prone areas via a numerical model of the mine.

One support option that may be appropriate for Uchucchacua Mine, would involve 0-gauge Screen Straps, installed with either Super SplitSets or $6 \mathrm{~m}$-long cable bolts to reinforce the mesh. The 12 gauge weldmesh that was in use in locations of potential seismic impact likely provided inadequate retaining capacity.

Static load-deformation capacities of weldmesh screening indicate that for bolting pattern $(1.2 \mathrm{~m} \times 1.2 \mathrm{~m})$, \#12 gauge mesh can support $1.36 \mathrm{t}$ of broken rock, while \#6 gauge mesh would support $3.18 \mathrm{t}$. At Uchucchacua Mine, a change from the current 12 gauge screening to a larger strand mesh ( \#8 gauge, or ideally \#6 gauge) for temporary (non-shotcreted) development at depth was advised to be considered.

\section{Conclusion}

This study allowed us to make recommendations that were later implemented in Uchucchacua Mine to improve the understanding of mechanisms associated with large seismic activity.

The recommendation scope ranged from rock mass characterisation, rock mass stress, ground support, quality control testing, safety aspects and microseismicity monitoring system update, in order to generate tools like a numerical model that could be useful to identify seismically prone locations, stress concentrations and risk assessment.

The integration of information from a variety of sources was useful to relate parameter as seismicity/ structure/mine geometry/mine (stoping) sequences with the events of collapse and observed rock mass damage.

The damage inspections and the interpretation of all data analysed permitted to identify the possible causes of the triggered seismic events, to make a diagnosis of the observed damage and to propose the following improvements and remediation tools as part of the mine activity: 
- Develop an intense stress measurement field test campaign in order to get information of the stress tensor, stress distribution and stress heterogeneity.

- Implement 3D numerical modelling, incorporating existing excavations, planned sequencing, lithology, prominent structural features, field stress distribution etc. in order to improve the awareness of stress distribution in the lower mine workings.

- Examine relationships between seismic events and resulting severity of excavation damage with respect to geological features.

- Geology information at depth was found to be useful to identify localised sectors of elevated quality, competent rock. Stress can accumulate in rock mass sectors (likely altered to marble), potentially leading to strain or pillar-burst type rockbursting.

Mitigation of damage associated with large magnitude seismic events:

- Implement improvements to primary support (mesh gauge size), particularly in locations reinforced by 'Temporary Support' standards. While these locations (example: stopes and stope accesses) are in use for a relatively short time period, they are also likely to be the sites most impacted by large magnitude seismic events.

- Tactical ground support design. Install appropriate dynamic support and/or deep reinforcement where it is needed. Establish a methodology utilising numerical modelling and microseismic assessment to identify at-risk sectors.

\section{References}

ASTM International 2013, Standard Specification for Roof and Rock Bolts and Accessories (ASTM F432-13), ASTM International, West Conshohocken.

Bieniawski, ZT 1989, Engineering Rock Mass Classification, New York, J Willey.

Buenaventura 2017, Estudio Geomecanico de la U.E.A. Uchucchacua, internal report, prepared by Departmento de Geologia Geomecanica, Mina Uchucchacua, 2017, 84 p.

CAMIRO Mining Division \& Mining Research Directorate 1995, Canadian Rockburst Research Program, 1990-1995, Vol. 2 (Rockburst Support), published by Canadian Mining Industry Research Organization Mining Division.

Castro, L, Carter, T \& Lightfoot, N 2009, 'Investigating factors influencing fault-slip in seismically active structures', in M Diederichs \& G Grasselli (eds), ROCKENG09: Proceedings of the 3rd CANUS Rock Mechanics Symposium, paper 4019.

DCR Ingenieros S.R. Ltda 2016, 'Evaluacion Geomecanica del Minado de Profundizacion, Mina Uchucchacua', Technical memo prepared by DCR Ingenieros S.R.Ltda, for Compañía de Minas Buenaventura S.A.A., Enero 2016, 231 p.

Diederichs, MS 1999, Instability of Hard Rockmasses: the Role of Tensile Damage and Relaxation, PhD thesis, University of Waterloo, Waterloo.

Hoek, E \& Brown, ET 1980, Underground Excavations in Rock, Institution of Mining and Metallurgy, London, 527 p.

Hoek, E, Kaiser, PK \& Bawden, WF 1995, Support of Underground Excavations in Hard Rock, A.A. Balkema, Rotterdam, 215 p.

Kaiser, PK \& Cai, M 2018, Rockburst Support Reference Book - Volume I: Rockburst Phenomenon and Support Characteristics, MIRARCO - Laurentian University, $284 \mathrm{p}$.

Kaiser, PK, McCreath, DR \& Tannant, DD 1996, Canadian Rockburst Support Handbook, Mining Research Directorate, Sudbury, Canada, $314 \mathrm{p}$.

Kaiser, PK, Diederichs, MS, Martin, CD, Sharp, J \& Steiner, W 2000, 'Underground works in hard rock tunneling and mining' Proceedings GeoEng2000: An International Conference on Geotechnical \& Geological Engineering, Technomic Publishing Co., vol. 1, pp. 841-926.

McCreath, DR \& Kaiser, PK 1992, 'Evaluation of current support practices in burst-prone ground and preliminary guidelines for Canadian hardrock mines', Proceedings of the International Symposium on Rock Support in Mining and Underground Construction, A.A. Balkema, Rotterdam, pp. 611-619.

Ortlepp, WD \& Stacey, TR 1994, 'Rockburst mechanisms in tunnels and shafts', Tunnelling and Underground Space Technology, vol. 9, no. 1, pp. 59-65.

Tomory, PE, Grabinsky, M, Curran, J \& Carvalho, J 1998, 'Factors influencing the effectiveness of SplitSet friction stabilizer bolts', CIM Bulletin, vol. 91, no. 1018, pp. 205-214. 